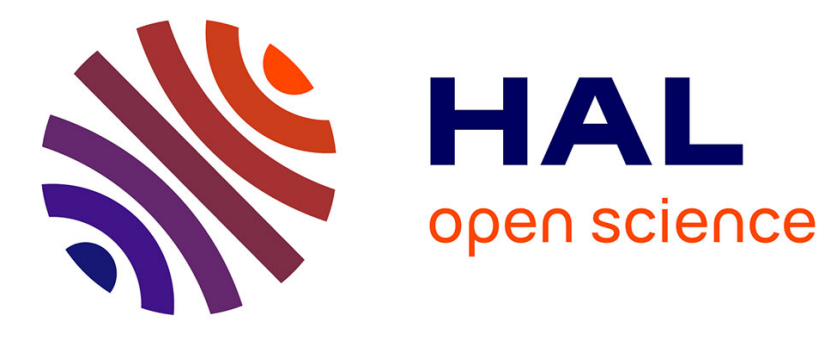

\title{
Faster and cleaner dynamic kinetic resolution via mechanochemistry
}

Thomas-Xavier Métro, Xavier Salom-Roig, Maëva Reverte, Jean Martinez, Frédéric Lamaty

\section{To cite this version:}

Thomas-Xavier Métro, Xavier Salom-Roig, Maëva Reverte, Jean Martinez, Frédéric Lamaty. Faster and cleaner dynamic kinetic resolution via mechanochemistry. Green Chemistry, 2015, 17 (1), pp.204208. 10.1039/c4gc01416b . hal-02336877

\section{HAL Id: hal-02336877 https://hal.science/hal-02336877}

Submitted on 29 Oct 2019

HAL is a multi-disciplinary open access archive for the deposit and dissemination of scientific research documents, whether they are published or not. The documents may come from teaching and research institutions in France or abroad, or from public or private research centers.
L'archive ouverte pluridisciplinaire HAL, est destinée au dépôt et à la diffusion de documents scientifiques de niveau recherche, publiés ou non, émanant des établissements d'enseignement et de recherche français ou étrangers, des laboratoires publics ou privés. 


\title{
Faster and cleaner dynamic kinetic resolution via mechanochemistry
}

\author{
Thomas-Xavier Métro,* Xavier J. Salom-Roig, Maëva Reverte, Jean Martinez and Frédéric Lamaty*
}

\begin{abstract}
Application of the ball-milling techniques to dynamic kinetic resolution accelerates reactions while avoiding the use of toxic organic solvents and reactants commonly required in these processes. In this way, dynamic kinetic resolutions can be both faster and "cleaner" in the sense that mechanochemistry enables the reduction of their environmental impact.
\end{abstract}

${ }_{10}$ Controlling the optical purity of molecules is essential in many areas, particularly in pharmaceutical research where biological activity highly depends on the chirality of active compounds. Numerous highly stereoselective methodologies have been developed to access enantiopure molecules and among them 15 kinetic resolution provides an attractive approach. In this process, two enantiomers of a racemate are transformed into chiral products at different rates. When the resolution is efficient, one of the enantiomers of the racemic mixture is transformed into the desired product while the other is recovered unchanged. 20 However, this procedure is limited to a maximum theoretical yield of $50 \%$. To overcome this limitation, an in situ epimerization of the chiraly labile substrate can be combined with the kinetic resolution to become a dynamic kinetic resolution (DKR). ${ }^{1}$ However, the inherent necessity for the speed of product ${ }_{25}$ formation to be slower than the substrate epimerization usually makes dynamic kinetic resolution quite a slow process.

$\alpha$-Halo carbonyls (A, Scheme 1) can be taken as a good illustration of this process: the configurationally labile halogen atom in the $\alpha$ position of the carbonyl can be irreversibly 30 substituted by a nucleophile. Stereo-differentiation in the $\mathrm{S}_{\mathrm{N}} 2$ halogen displacement can be controlled by the chiral environment on $\mathrm{R}_{2}$.

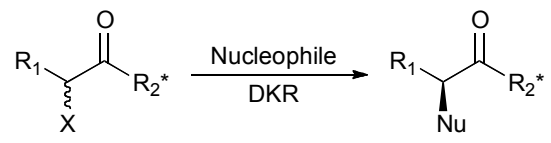

A
Scheme 1 Dynamic kinetic resolution of $\alpha$-halo carbonyls by $\mathrm{S}_{\mathrm{N}} 2$ halogen 40 displacement.

Whereas DKR of such substrates allow access to products of type B with good yield and diastereoselectivity, long reaction times are needed. As many other examples of $\mathrm{S}_{\mathrm{N}} 2$ reactions, these DKR require polar and aprotic solvents such as toxic DCM or THF, ${ }^{2}$

45 and are performed with organic, toxic and corrosive bases such as $\mathrm{Et}_{3} \mathrm{~N}$ to epimerise the substrate. ${ }^{3}$ Thus, reaction conditions allowing shorter reaction times and avoiding the use of problematic solvents and reagents would be highly preferable. Following our general objective to find greener alternatives to ${ }_{50}$ otherwise environmentally troublesome chemical reactions, ${ }^{4}$ we envisioned performing DKR avoiding the use of undesirable solvents and bases. Due to its relevance for a laboratory scale study, the Ecoscale score ${ }^{5}$ was chosen as the green metric of choice to evaluate the environmental impact of the new reaction ${ }_{55}$ conditions. The Ecoscale is a score ranging from 0 (totally failed reaction) to 100 (ideal reaction) that is based on yield, cost, safety, technical set up, temperature and time of reaction, work up and purification aspects. To each of these parameters are attributed penalty points that are subtracted to the ideal score of 60100 to give the Ecoscale score of the studied reaction. The reaction conditions are ranked excellent if Ecoscale score is $>75$, acceptable if $>50$ and inadequate if $<50$.

As a first example, we studied the DKR reaction of $\alpha$-bromo(R)-pantolactone ester 1 with $\mathrm{Bn}_{2} \mathrm{NH}$ that was previously ${ }_{65}$ described by Durst and coworkers. ${ }^{6}$ Thus, we treated compound $\mathbf{1}$ with $\mathrm{Et}_{3} \mathrm{~N}$, a catalytic amount of TBAI and $\mathrm{Bn}_{2} \mathrm{NH}$ to obtain the corresponding $\alpha$-dibenzylamino ester $\mathbf{2 a}$ in $59 \%$ yield with an excellent diastereoisomeric ratio (>98:2) (Table 1, entry 1). As described in the literature, this reaction was set up using an 70 excess of $\mathrm{Et}_{3} \mathrm{~N}$ ( $2.0 \mathrm{eq}$ ) in a toxic solvent (THF is suspected to be carcinogenic), accounting for a low Ecoscale score of 42.5, which corresponds to an inadequate synthesis. ${ }^{5}$ To improve the environmental impact of this reaction, we envisioned replacing the problematic $\mathrm{Et}_{3} \mathrm{~N}$ and THF with innocuous $\mathrm{NaHCO}_{3}$ and 75 water. ${ }^{7}$ Under these conditions, the Ecoscale score was hardly improved to 54 , mainly due to a low yield of $34 \%$ (50\% brsm; Table 1, entry 2). In addition, the reaction was much slower as 6 h were necessary to reach $50 \%$ conversion and 2 a was obtained with a lower diastereomeric ratio (87:13). When a preferable ${ }_{80}$ solvent such as $\mathrm{EtOAc}^{8}$ was used in place of water, the reaction proceeded with a satisfying Ecoscale score of 62.5, and furnished 2a in a good yield of $73 \%$ with an excellent diastereomeric ratio $(>98: 2)$ (Table 1, entry 3). Even when careful attention was paid to use the minimum amount of solvent enabling proper agitation ${ }_{85}$ of this heterogeneous reaction media, 6 days were necessary to reach full conversion of the substrate. At this point of the study, we considered that keeping innocuous $\mathrm{NaHCO}_{3}$ as base would force us to use more polar solvents such as EtOH, THF or DMF. The use of THF or EtOH as solvents was disappointing since $24 \mathrm{~h}$ 90 and more than 6 days of reaction were respectively required to reach $95 \%$ of conversion (Table 1, entries 4 and 5). The use of DMF as solvent resulted in a much shorter reaction time; only $2 \mathrm{~h}$ were required for a complete consumption of substrate $\mathbf{1}$ (Table 1, entry 6). Nevertheless, an unsatisfying Ecoscale score of 50.5 95 was obtained mainly due to the low yield (55\%) and the fact that DMF presents high health-related risks, which hamper its environmental impact. ${ }^{9}$ Excepted for DMF, these relatively long reaction times could be attributed to the low solubility of either $\mathrm{NaHCO}_{3}$ in organic solvents or $\alpha$-bromo ester $\mathbf{1}$ in water, 100 resulting in heterogeneous reaction mixtures that may lead to mass transfer limitations. As heterogeneity of the reaction mixture could be responsible for a low speed of reaction, the transformation was performed using the ball-milling technology. ${ }^{10}$ In this kind of apparatus, reagents (liquid or solid) 105 are introduced into a jar with one or more balls. Rapid movements of the jar create repeated and violent contacts between reagents, balls and walls allowing for a very efficient mixing of solid-containing reaction mixtures. 


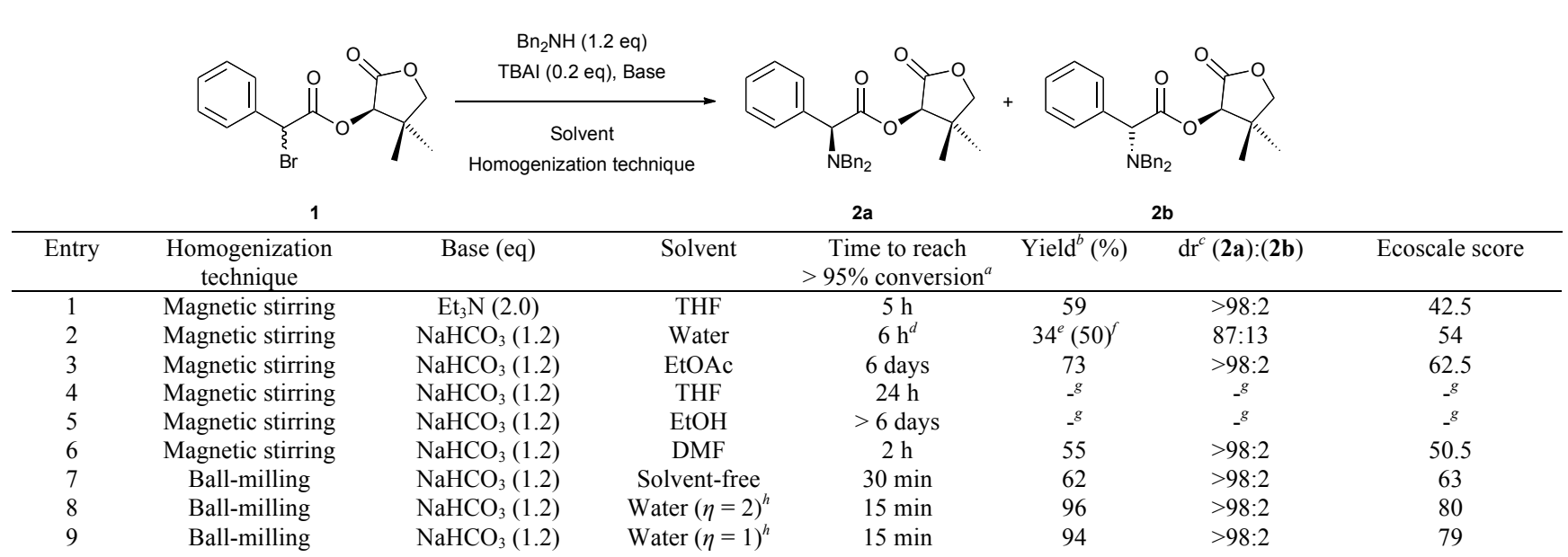

${ }^{a}$ Determined by HPLC. ${ }^{b}$ Isolated yield. ${ }^{c}$ Determined using $300 \mathrm{MHz}{ }^{1} \mathrm{H}$ NMR. ${ }^{d}$ Time to reach $50 \%$ conversion. ${ }^{e}$ Obtained as a $50: 50$ molar mixture of 2a:2b and 1. ${ }^{f}$ Based on recovered starting material (brsm). ${ }^{g}$ Not determined. ${ }^{h}$ The $\eta$ ratio is defined as the amount of added liquid to the sum of the mass of reactants. It is expressed in $\mu \mathrm{L} \mathrm{mg}^{-1}$.

${ }_{5}$ Indeed, $30 \mathrm{~min}$ of vigorous agitation were enough for a complete conversion of $\alpha$-bromo ester $\mathbf{1}$ into amino-ester $\mathbf{2 a}$ when $\mathbf{1}$ was placed in a $10 \mathrm{~mL}$ jar with one $10 \mathrm{~mm}$ diameter ball, $\mathrm{NaHCO}_{3}$, dibenzylamine, and TBAI in the absence of any solvent (Table 1, entry 7). Under these conditions, dibenzylamino ester 2a was 10 isolated in $62 \%$ yield with an excellent diastereomeric ratio (>98:2) and a satisfying Ecoscale score of 63. Obtainable benefits from adding a liquid in a grinded reaction mixture are now well established. ${ }^{10 b, 11,12}$ Indeed, when adding small amounts of water in the jar $\left(\eta \text { ratio of } 2 \mu \mathrm{L} \mathrm{mg}^{-1}\right)^{13}$ only 15 min were necessary to 15 obtained complete conversion of the substrate while dibenzylamino ester 2a was isolated in excellent yield and diastereomeric ratio ( $96 \%$ yield, $\mathrm{dr}>98: 2$; Table 1 , entry 8 ). In these conditions, the highest Ecoscale score was obtained (80), corresponding to an excellent synthesis. ${ }^{5}$ Calculations leading to 20 this high Ecoscale score include solvent used during work-up and chromatographic purification (details on the Ecoscale calculations are available in the ESI). Reducing the amount of water in the reaction media to $1 \mu \mathrm{L} \mathrm{mg}^{-1}$ had little effect on the course of the reaction as $\mathbf{2 a}$ was obtained in $94 \%$ yield and $>98: 2 \mathrm{dr}$ (Table 1 ,

25 entry 9). We postulate that solving the suspected mass transfer limitations by using the tremendous ability of the ball-mill technology to mix solid-containing mixtures allowed:

- improvement of the yield without hampering the diastereoselectivity

$30 \quad-\quad$ reduction of reaction time

- utilisation of the least problematic base $\left(\mathrm{NaHCO}_{3}\right)$ and solvent $\left(\mathrm{H}_{2} \mathrm{O}\right)$ regardless of their solubility or solubilizing capacities.

To our knowledge, this is the first example of DKR to be ${ }_{35}$ performed through ball-milling technology.

At this stage of the study, we became interested in comparing the efficiency and the environmental impact of solution-based DKR reactions with the mechanochemistry-mediated approach on other known DKR reactions implying a $\mathrm{S}_{\mathrm{N}} 2$ halogen substitution. ${ }_{40}$ When treated with $(S)-(-)$ - $\alpha$-methylbenzylamine in THF in the presence of $\mathrm{Et}_{3} \mathrm{~N}$ as base, $\alpha$-bromo ester $\mathbf{1}$ was transformed into 3 in $84 \%$ yield and $>98: 2 \mathrm{dr}$ (Table 2 , entry 1 ). ${ }^{6}$ The use of THF and $\mathrm{Et}_{3} \mathrm{~N}$ resulted in a low Ecoscale score of 52. Replacing these problematic chemicals with water and $\mathrm{NaHCO}_{3}$ while mixing the ${ }_{45}$ reaction mixture with a vibrating ball-mill allowed for the production of $\mathbf{3}$ with much better Ecoscale score (72), high yield $(80 \%)$ and diastereoselectivity (>98:2) (Table 2, entry 2). Treating $\alpha$-bromo ester 1 with $p$-anisidine in classical solutionbased approach ${ }^{6}$ furnished amine 4 in $75 \%$ yield and $>98: 2 \mathrm{dr}$, ${ }_{50}$ though with a low Ecoscale score of 40.5 . When applying our ball-mill mediated approach, Ecoscale score could be improved up to 54, yet with a slightly lower yield (64\%) and a drop in diastereoselectivity $(88: 12)$ (Table 2, entry 4). Oxygen-based nucleophiles such as $p$-methoxyphenol could also be used to ${ }_{55}$ perform DKR on $\alpha$-bromo ester 1. Indeed, Durst and coworkers utilised $\mathrm{NaH}$ and THF to produce $\mathbf{5}$ with 70\% yield and 95:5 dr, yet with a low Ecoscale score of 41 (Table 2, entry 5). ${ }^{14}$ Treatment of $\alpha$-bromo ester 1 with $p$-methoxyphenol in a ballmill with water and $\mathrm{NaHCO}_{3}$ instead of THF and $\mathrm{NaH}$ resulted in 60 the production of ester $\mathbf{5}$ with a better yield and Ecoscale score of $86 \%$ and 62 respectively, albeit with a moderate $72: 28 \mathrm{dr}$ (Table 2, entry 6). When 2,6-dichlorophenol was used as nucleophile, reaction time, diastereoselectivity and Ecoscale score were improved while the yield remain similar (Table 2, entries 7 and $\left.{ }_{65} 8\right) .{ }^{15}$ After having changed the nature of nucleophiles, we focused our attention on other types of substrate such as $\alpha$-bromo amide 7 and $\alpha$-bromo ketone 9 .

When 1-(2-bromo-1-oxopropyl)-L-proline methyl ester 7 was reacted with $\mathrm{Bn}_{2} \mathrm{NH}$ in $\mathrm{CH}_{2} \mathrm{Cl}_{2}$ in the presence of $\mathrm{Et}_{3} \mathrm{~N}$ for $24 \mathrm{~h}$, $70 \mathrm{~N}, \mathrm{~N}$-dibenzyl-D-alanyl-L-proline methyl ester $\mathbf{8}$ was obtained in $81 \%$ yield with $87: 13 \mathrm{dr}$, accounting for an Ecoscale score of 51 (Table 2, entry 9). ${ }^{16}$ Once again, utilising the ball-milling technology avoided the use of problematic $\mathrm{CH}_{2} \mathrm{Cl}_{2}$ and $\mathrm{Et}_{3} \mathrm{~N}$. Thus, the reaction of $\alpha$-bromo amide 7 with $\mathrm{Bn}_{2} \mathrm{NH}$ in the 75 presence of $\mathrm{NaHCO}_{3}$ and water in a vibrating ball-mill furnished product $\mathbf{8}$ with a similar yield $(75 \%)$ and an improvement in the Ecoscale score was obtained (68.5 vs 51 with the solution-based approach) (Table 2, entry 10). It is worth noting that utilisation of the ball-mill also resulted in improving the diastereomeric ratio 80 from $87: 13$ to $>98: 2$. 
Table 2 Comparison of classical solvent-based approaches with mechano-mediated DKR

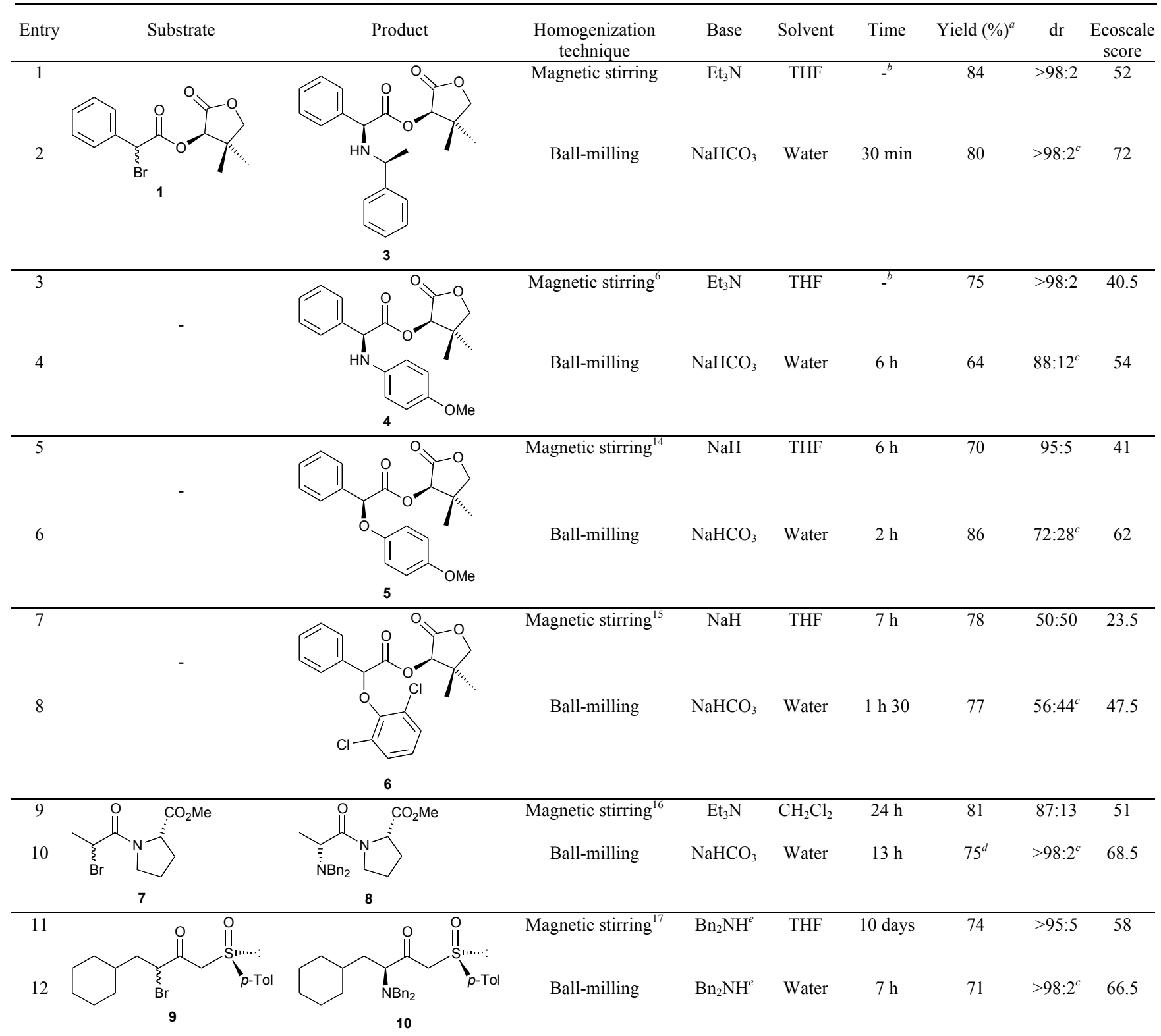

${ }^{a}$ Isolated yield. ${ }^{b}$ Not indicated in the original publication. ${ }^{c}$ Diastereomeric ratios were determined using $300 \mathrm{MHz}{ }^{1} \mathrm{H}$ NMR. ${ }^{d} 2.16$ eq of Bn ${ }_{2} \mathrm{NH}$ were used. ${ }^{e} 2.5$ eq of $\mathrm{Bn}_{2} \mathrm{NH}$ were used.

Finally, this approach was applied to the DKR reaction of ${ }_{5} \gamma$-bromo- $\beta$-ketosulfoxide 9 with $\mathrm{Bn}_{2} \mathrm{NH}$. Salom-Roig and coworkers ${ }^{17}$ reported that treatment of 9 with 2.5 equivalents of $\mathrm{Bn}_{2} \mathrm{NH}$ required 10 days in THF to reach reaction completion furnishing $\gamma$-dibenzylamino- $\beta$-ketosulfoxide 10 with $74 \%$ yield and $>95: 5 \mathrm{dr}$ (Table 2, entry 11). By using $\mathrm{Bn}_{2} \mathrm{NH}$ as nucleophile 10 and base to deprotonate the $\mathrm{HBr}$ salts produced during the course of the reaction, the authors already avoided the use of the flammable, corrosive and toxic $\mathrm{Et}_{3} \mathrm{~N}$, thus improving the environmental impact of the reaction. This particularity resulted in a good Ecoscale score of 58. Yet, when the same reaction was 15 performed in a ball-mill with water replacing THF, time for reaction completion were dramatically reduced to only $7 \mathrm{~h}$, while furnishing $\gamma$-dibenzylamino- $\beta$-ketosulfoxide $\mathbf{1 0}$ with a similar yield of $71 \%$ and diastereoselectivity (Table 2, entry 12).
Replacing THF with water and reducing the required time to 20 reach reaction completion resulted in an Ecoscale score improvement up to 66.5 .

\section{Conclusions}

In conclusion, the great capacity of the ball-milling technology to mix solid-containing reaction mixtures allowed the design of ${ }_{25}$ reaction conditions that could mitigate the environmental impact of dynamic kinetic resolutions. This reduction was evaluated by calculating the Ecoscale score of every studied reaction conditions. Thus, we have shown that problematic chemicals such as THF or $\mathrm{Et}_{3} \mathrm{~N}$ could be replaced by innocuous water and $30 \mathrm{NaHCO}_{3}$ without dramatically hampering the performance of the DKR reactions. In all cases, time required to go to completion was severely reduced and in some cases yields and/or 
diastereomeric ratios were also improved. Exemplification of utilisation of the ball-milling technology to reduce the environmental impact of other problematic reactions is currently under progress.

We thank CNRS, Université Montpellier 1 and Université Montpellier 2 for financial support. François Métro is gratefully acknowledged for producing graphical abstract artwork.

\section{${ }_{10}$ Notes and references}

Institut des Biomolécules Max Mousseron (IBMM), UMR 5247 CNRS Universités Montpellier 1 et 2-ENSCM, Bâtiment Chimie (17), Université Montpellier 2, Place Eugène Bataillon, 34095 Montpellier cedex 5 , France. Fax: (+33) 4-6714-4866; E-mail: txmetro@univ-montp2.fr, 15 frederic.lamaty@univ-montp2.fr

$\uparrow$ Electronic Supplementary Information (ESI) available: General experimental procedures, characterisation data of all synthesized compounds and details on the calculations of Ecoscale scores.

${ }^{1}$ (a) H. Pellissier, Tetrahedron, 2003, 59, 8291-8327; (b) H. Pellissier, Tetrahedron, 2008, 64, 1563-1601; (c) Y. S. Park, Tetrahedron: Asymmetry, 2009, 20, 2421-2427; (d) H. Pellissier, Tetrahedron, 2011, 67, 3769-3802.

${ }^{2}$ DCM stands for dichloromethane and THF for tetrahydrofuran. DCM and THF are classified as toxic and carcinogenic (Category 2) according to Regulation (EC) No 1272/2008.

${ }^{3}$ Triethylamine is classified as highly flammable (R11), corrosive (R35) and harmful (R20/21/22) according to EU Directives 67/548/EEC or 1999/45/EC

${ }^{4}$ (a) V. Declerck, P. Nun, J. Martinez and F. Lamaty, Angew. Chem. Int. Ed., 2009, 48, 9318-9321; (b) T.-X. Métro, J. Bonnamour, T. Reidon, J. Sarpoulet, J. Martinez and F. Lamaty, Chem. Commun., 2012, 48, 1178111783; (c) J. Bonnamour, T.-X. Métro, J. Martinez and F. Lamaty, Green Chem., 2013, 15, 1116-1120.

${ }^{5}$ K. Van Aken, L. Strekowski and L. Patiny, Beilstein J. Org. Chem., 2006, 2, 3 .

${ }^{6}$ R. N. Ben and T. Durst, J. Org. Chem., 1999, 64, 7700-7706. Reaction times were not indicated in the publication.

${ }^{7} \mathrm{NaHCO}_{3}$ is considered to be a not hazardous substance as defined by the European regulation $\mathrm{N}^{\circ} 1272 / 2008$ and not classified as dangerous according to Directive 67/548/EEC.

${ }^{8}$ (a) K. Alfonsi, J. Colberg, P. J. Dunn, T. Fevig, S. Jennings, T. A. Johnson, H. P. Kleine, C. Knight, M. A. Nagy, D. A. Perry and M. Stefaniak, Green Chem., 2008, 10, 31-36; (b) R. K. Henderson, C. Jiménez-González, D. J. C. Constable, S. R. Alston, G. G. A. Inglis, G. Fisher, J. Sherwood, S. P. Binks and A. D. Curzons, Green Chem., 2011 13, 854-862; (c) D. Prat, O. Pardigon, H.-W. Flemming, S. Letestu, V. Ducandas, P. Isnard, E. Guntrum, T. Senac, S. Ruisseau, P. Cruciani and P. Hosek, Org. Process Res. Dev., 2013, 17, 1517-1525.

${ }^{9} \mathrm{DMF}$ is classified as presenting reproductive toxicity according to Regulation (EC) No 1272/2008.

${ }^{10}$ (a) B. Rodríguez, A. Bruckmann, T. Rantanen and C. Bolm, Adv. Synth. Catal., 2007, 349, 2213-2233; (b) S. L. James, C. J. Adams, C. Bolm, D. Braga, P. Collier, T. Friščić, F. Grepioni, K. D. M. Harris, G. Hyett, W. Jones, A. Krebs, J. Mack, L. Maini, A. G. Orpen, I. P. Parkin, W. C. Shearouse, J. W. Steed and D. C. Waddell, Chem. Soc. Rev., 2012, 41, 413-447; (c) G. W. Wang, Chem. Soc. Rev., 2013, 42, 7668-7700.

${ }^{11}$ (a) E. Boldyreva, Chem Soc Rev, 2013, 42, 7719-7738; (b) G. A. Bowmaker, Chem. Commun., 2013, 49, 334-348.

${ }^{12}$ T. Friščić, S. L. Childs, S. A. A. Rizvi and W. Jones, CrystEngComm, 2009, 11, 418-426.

${ }^{13}$ The $\eta$ ratio is defined as the amount of added liquid to the sum of the mass of reactants. It is expressed in $\mu \mathrm{L} \mathrm{mg}^{-1}$.

${ }^{14}$ K. Koh and T. Durst, J. Org. Chem., 1994, 59, 4683-4686.
${ }^{15}$ G. Massolini, G. Fracchiolla, E. Calleri, G. Carbonara, C. Temporini, A. Lavecchia, S. Cosconati, E. Novellino and F. Loiodice, Chirality, 2006, 18, 633-643.

${ }^{16}$ J. Nam, J.-Y. Chang, K.-S. Hahm and Y. S. Park, Tetrahedron Lett., 2003, 44, 7727-7730.

${ }^{17}$ P.-Y. Géant, J. Martinez and X. J. Salom-Roig, Eur. J. Org. Chem., 2011, 1300-1309. 